\title{
Presymptomatic detection and prenatal diagnosis for myotonic dystrophy by means of linked DNA markers
}

\author{
A M NORMAN, J L FLOYD, A L MEREDITH, AND P S HARPER \\ From the Institute of Medical Genetics, University of Wales College of Medicine, Heath Park, Cardiff \\ CF4 $4 X N$.
}

SUMmary The close genetic linkage between the loci for apolipoprotein CII (ApoCII) and myotonic dystrophy makes presymptomatic detection and prenatal diagnosis feasible. We report three years' service experience of providing presymptomatic detection and prenatal diagnosis for myotonic dystrophy in 99 families. Careful clinical study of older family members remains important. The introduction of new probes (CKMM and BCL4) has helped to solve the problem of uninformativeness owing to unhelpful genotype distribution in a family. Nevertheless, informativeness cannot be guaranteed and families should be studied before pregnancy is undertaken whenever possible.

Presymptomatic testing and prenatal diagnosis for myotonic dystrophy are soundly based. All affected subjects should have DNA banked for future use when other family members may require genotype information.

Myotonic dystrophy is an autosomal dominant disorder with a prevalence of approximately 5 per $10^{5}$ population. Grip myotonia, polychromatic cataracts, frontal balding, and muscle weakness are well known features but the absence of these features does not exclude the presence of the myotonic dystrophy gene. ${ }^{2}$ The age of onset and degree of severity are highly variable so that young adults with an affected parent may carry the gene despite apparent clinical normality. Therefore, determination of carrier status by using RFLPs that are genetically linked to myotonic dystrophy may be of value. ${ }^{3}$ A further problem is that affected mothers run a high risk of giving birth to congenitally affected infants. ${ }^{4}$ Congenital myotonic dystrophy is characterised by neonatal hypotonia, respiratory difficulties, and mental retardation, and early death may occur. ${ }^{5}$ Prenatal diagnosis may therefore be requested by couples at risk for this form. ${ }^{6}$

Myotonic dystrophy had been known for some time to be linked to the secretor and Lutheran blood group loci, ${ }^{7}$ before the discovery of linkage to $\mathrm{C} 3$ placed the linkage group on chromosome $19 .{ }^{8}$ The cDNA for ApoCII has been shown to be localised

Received for publication 26 May 1989.

Revised version accepted for publication 30 June 1989. sufficiently close to the myotonic dystrophy gene that prediction of clinical status can be made with a high degree of accuracy by following the inheritance of alleles of ApoCII through family pedigrees. ${ }^{9}$ From the beginning of 1986 we have used this probe, together with a genomic derivative probe, pSC11, on a clinical service basis to determine carrier status and offer prenatal diagnosis. In 1986 we reported the initial results in seven myotonic families who were referred to us for prenatal diagnosis or carrier detection using RFLPs. ${ }^{3}$ More recently two additional probes, $\mathrm{CKMM}^{10}$ and $\mathrm{BCL} 4,{ }^{11}$ have also been used diagnostically, the former having been shown to be closer to the myotonic dystrophy gene. We report here our three year experience of this service; the figures include the original seven families already reported. ${ }^{3}$

\section{Methods}

Families were referred from all over the United Kingdom and also from abroad, usually by a clinical geneticist, but occasionally by neurologists or paediatricians. Blood samples, collected in EDTA, from relevant family members were sent by first class post and chorionic villus samples were sent, where appropriate, by courier. Clinical data, pedi- 
gree data, and blood samples were all provided by the referring centre.

\section{DNA ANALYSIS}

DNA was extracted from venous blood and digested to completion with the appropriate restriction endonuclease (TaqI, BanI, Bam HI, BgII, NcoI, or $M l u I$ with EcoRI). The DNA fragments were size fractionated by electrophoresis on $0 \cdot 8 \%$ agarose gels. DNA was transferred onto nylon filters (Hybond-N, Amersham) by the method of Southern. The filters were hybridised with ${ }^{32} \mathrm{P}$ radiolabelled probes. Excess radiolabel was removed by washing filters at $65^{\circ} \mathrm{C}$ in $2 \times \mathrm{SSC}$ (SSC $0.15 \mathrm{~mol} / 1$ sodium chloride, $0.015 \mathrm{~mol} / \mathrm{l}$ sodium citrate) down to $0 \cdot 1 \times$ SSC as required. Autoradiography was carried out using Fuji $x$ ray film with intensifying screens at $-70^{\circ} \mathrm{C}$ for one to seven days. ${ }^{12}$

The probes and RFLPs used are summarised in table 1. Allele frequency data are based on analysis of all families collected both for research and service indications in Cardiff. ${ }^{13}$ Criteria for establishing the validity of genetic recombination in myotonic dystrophy have recently been published. ${ }^{14}$ Risk calculation using marker results was generally straightforward. We used a recombination frequency of $2 \mathrm{cM}$ for CKMM and $4 \mathrm{cM}$ for other probes. Where appropriate information from a life table ${ }^{1}$ was incorporated into the final risk by Bayesian calculation, but generally this would not much alter the final risk value given to a young adult.

\section{Results}

Ninety-nine families were referred for analysis; 56 subjects wished clarification of carrier status and 73 affected subjects wished to know if they would be informative for prenatal diagnosis. In addition, 16 prenatal diagnostic tests have been completed. Results are summarised in tables 2,3 , and 4 .

TABLE 1 Probes used for assigning carrier status and/or assessing informativeness for prenatal diagnosis.

\begin{tabular}{|c|c|c|c|c|c|}
\hline \multirow{2}{*}{$\begin{array}{l}\text { Probe } \\
\text { name }\end{array}$} & \multirow[t]{2}{*}{ Enzyme } & \multicolumn{2}{|c|}{ Allele sizes $(k b)$} & \multicolumn{2}{|c|}{ Allele frequency* } \\
\hline & & 1 & 2 & 1 & 2 \\
\hline \multirow[t]{4}{*}{ ApoCII } & TaqI & $3 \cdot 8$ & $3 \cdot 2$ & 0.59 & 0.41 \\
\hline & BanI & $2 \cdot 5$ & 1.6 & 0.68 & $0 \cdot 32$ \\
\hline & BamHI & $4 \cdot 0$ & $6 \cdot 0$ & 0.90 & $0 \cdot 10$ \\
\hline & NcoI & $14 \cdot 5$ & $11 \cdot 5$ & $0 \cdot 30$ & 0.70 \\
\hline pSC11 & $B g I I$ & $12 \cdot 0$ & $9 \cdot 0$ & 0.47 & 0.53 \\
\hline \multirow[t]{2}{*}{ CKMM } & TaqI & $4 \cdot 3$ & $4 \cdot 2$ & $0 \cdot 28$ & 0.72 \\
\hline & NcoI & $3 \cdot 3$ & $2 \cdot 3$ & $0 \cdot 32$ & 0.68 \\
\hline \multirow[t]{2}{*}{ BCLA } & BanI & $3 \cdot 0$ & $2 \cdot 2$ & 0.72 & 0.28 \\
\hline & MluI/EcoRI & $9 \cdot 0$ & $8 \cdot 0$ & 0.71 & 0.29 \\
\hline
\end{tabular}

ApoCII, pSC11, BCL4 recombination frequency 0-04, CKMM recombination frequency 0.02 .

*Allele frequency data based on all families studied in Cardiff. ${ }^{13}$
TABLE 2 Presymptomatic tests April 1987 to April 1989.

\begin{tabular}{lr}
\hline Total No of subjects requesting test & 56 \\
No of families involved & 48 \\
Females & 32 \\
Males & 24 \\
Outcome of test definitive & 4 \\
$\quad$ High risk genotype & 30 \\
Low risk genotype & \\
Outcome of test inconclusive & 8 \\
$\quad$ Failure to decide which parent affected & 4 \\
$\quad$ Unsuitable pedigree structure & 10 \\
$\quad$ No informative probe & \\
\hline
\end{tabular}

TABLE 3 Informativeness for prenatal diagnosis April 1987 to April 1989.

\begin{tabular}{lc}
\hline Total No of subjects requesting information & 73 \\
No of families involved & 61 \\
Females affected & 55 \\
Males affected & 18 \\
Couple $100 \%$ informative & 28 \\
Affected subject informative, but no spouse yet & 22 \\
Couple 50\% informative & 6 \\
Failure to decide phase & 3 \\
Recombination identified & 2 \\
Uninformative for all polymorphisms & 1 \\
Uninformative for original polymorphisms & \\
$\quad$ (not yet retested for CKMM and BCL4) & 11 \\
\hline
\end{tabular}

TABle 4 Prenatal diagnoses since April 1986.

\begin{tabular}{lc}
\hline Total requested & 16 \\
Mother affected & 12 \\
Father affected & 4 \\
Testing for informativeness preceded pregnancy & 7 \\
Pregnancy preceded receipt of samples & 9 \\
Miscarriage preceded any procedure & 5 \\
Chorionic villus sampling & 7 \\
Amniocentesis & 3 \\
No informative probe & 1 \\
High risk fetus & 3 \\
High risk fetus terminated & 2 \\
High risk fetus, pregnancy continued. child congenitally affected & 1 \\
Low risk fetus & 4 \\
Essential family members dead. no alteration of risk possible & 2 \\
Amniocytes failed to grow (sent from abroad) & 1 \\
\hline
\end{tabular}

\section{ILLUSTRATIVE FAMILIES}

Some examples of interpretation of the data together with problems which have occurred are illustrated in the following families.

Example 1 (fig la). Prediction in a sibship with childhood onset. (Referred by Professor M Bobrow, Guy's Hospital, London.)

The proband was diagnosed as having myotonic dystrophy at the age of 6 years, having had slow motor development with early feeding difficulties and requiring special education. Myotonic dystrophy was confirmed in the mother at this time. Testing 


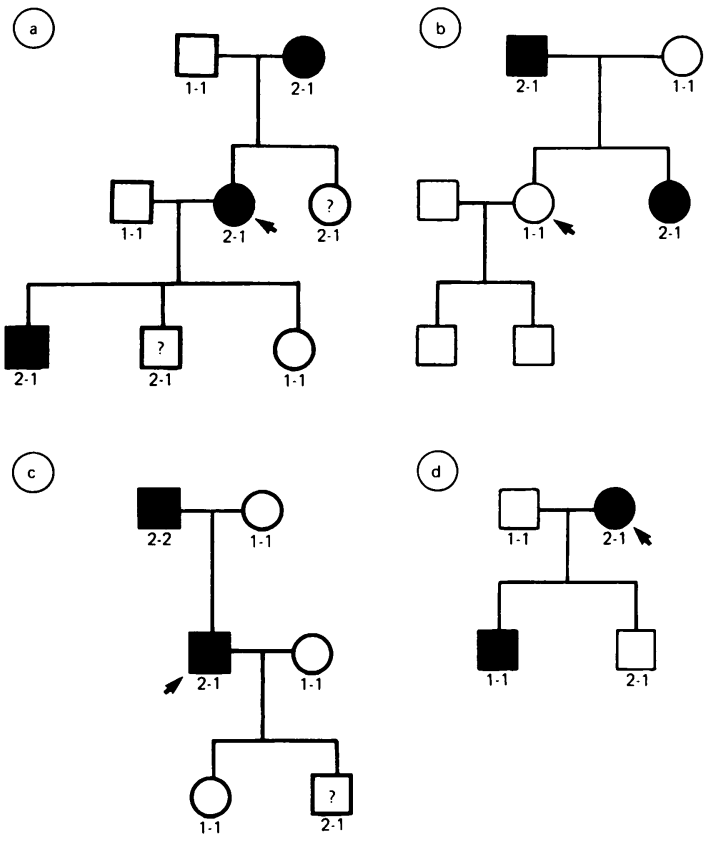

FIG 1 Pedigrees of families described in examples 1 to 4. (a) Example 1, (b) example 2, (c) example 3, (d) example 4. The numbers refer to the RFLP markers described in the text.

was requested for the other children, aged 5 and 1 years, especially since the middle child had a suspicion of facial weakness. The mother's sister, aged 25, was anxious to know her status. The results of genotyping (ApoCII/BamHI) showed that the second child had indeed inherited the same marker genotype as his affected brother, while the younger sister, who was clinically entirely normal, had inherited the opposite genotype. Investigation of the mother's sister, who was clinically normal, showed that not only had she inherited the same genotype as her affected sister, but that she showed myotonic potentials on EMG and lens opacities on slit lamp examination. Note that the tests on the young children in this family were done in relation to their own health, not for establishing their genetic status for the future. In the family context of a sibship with childhood onset, it would have been difficult to omit testing the entirely healthy sister.

Example 2 (fig 1 b). Exclusion of myotonic dystrophy in a person at $50 \%$ risk. (Referred by Professor R H T Edwards, University of Liverpool.)

The proband, whose father and sister were both affected, was herself symptom free aged 37 , but was concerned that her children, aged 7 and 3 years, might develop the disorder should she carry the gene. It can be seen that the marker genotypes (ApoCII/BanI) show that she has received the opposite marker allele from her father to that inherited by her affected sister. This result, taken in conjunction with the age of the proband and the normal result of other investigations, reduces her risk to around $1 \%$, allowing an even smaller risk to be given to her children. Even though the main concern here was for the children, it was the mother who was the appropriate person on whom to focus investigations.

Example 3 (fig 1c). Predictive testing in childhood.

The son of the proband was first seen aged 4 years together with his 6 year old sister after his parents requested genetic counselling on account of the father's myotonic dystrophy. Clinical examination of both children was normal and remained so on regular assessment until the age of 12 years, when the son complained of intermittent muscle stiffness and a suspicion of facial weakness was noted. There was no clinical myotonia and slit lamp examination of the lens was normal, but the parents were reluctant for him to undergo EMG. After discussiorg with the parents and son it was decided to undertake DNA analysis, which showed that the son had inherited the high risk marker (ApoCII/BanI) geno type from his father, in contrast to the daughter. EMG was done later and showed definite myotonic potentials. The sister, who was now aged 15 and neurologically normal, had a normal EMG. Molecular testing was not undertaken until the development of symptoms suggestive of myotonic dystrophy. The family were concerned that the brother and sister should be tested together.

Example 4 (fig 1d). Prediction for sibs of a patient with congenital myotonic dystrophy. (Referred by Professor M Bobrow.)

The first son of the proband was affected by congenital myotonic dystrophy; the second son, aged 3 years, was clinically unaffected and the parents wished to have prenatal diagnosis in future pregnancies. Although phase cannot be established with certainty, the second son has the opposite allele of ApoCII/TaqI to his affected brother, reducing his chance of having inherited myotonic dystrophy to $8 \%$ (or $2 \%$ if the life table for sibs of congenital myotonic dystrophy is taken into account). The situation is informative for future prenatal diagnosis.

Example 5 (fig 2a). Prediction for prenatal informativeness. (Referred by Dr J Burn, Newcastle upon Tyne.) 


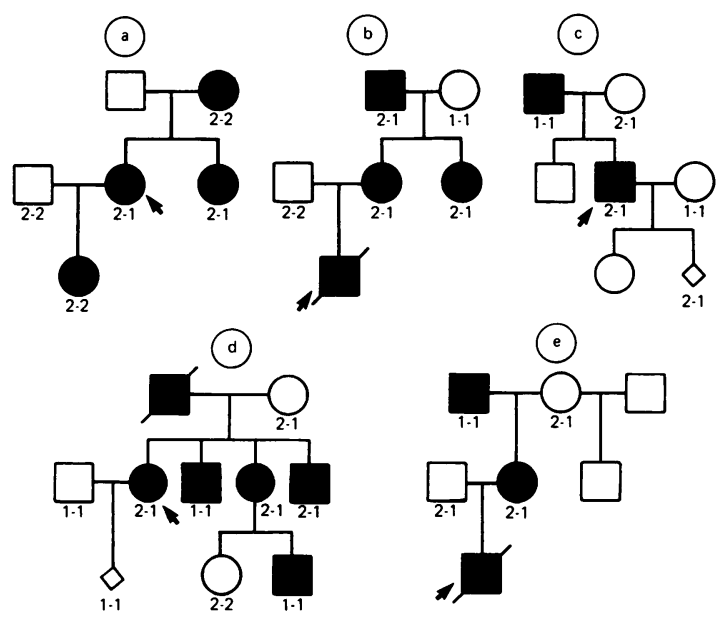

FIG 2 Pedigrees of families described in examples 5 to 9. (a) Example 5, (b) example 6, (c) example 7, (d) example 8 , (e) example 9. The numbers refer to the RFLP markers described in the text.

The first child of the proband was affected by congenital myotonic dystrophy, and information was requested as to whether prenatal diagnosis would be feasible in a future pregnancy. It can be seen that the myotonic dystrophy gene in this family is being transmitted with allele 2 of the marker locus ApoCII/BanI. The fact that the affected grandmother is homozygous 2-2 for the marker establishes phase for her daughters, while the husband being homozygous makes this a fully informative situation. In a future pregnancy a fetus typing 2-1 would have its risk of inheriting the gene reduced from $50 \%$ to $4 \%$, while a $2-2$ fetus would have a $96 \%$ chance of being affected, with a high probability also of being severely affected like the first child. Prenatal diagnosis will also be feasible for pregnancies of the younger sister, though her future spouse will require typing.

Example 6 (fig $2 b$ ). Informativeness for prenatal diagnosis. (Referred by Dr G Kohn, Edith Wolfson Hospital, Israel.)

The proband died of congenital myotonic dystrophy aged 5 days, the mother and other affected family members being diagnosed after this. The family is fully informative for prenatal diagnosis in a future pregnancy, with the risk increasing to $98 \%$ for a $2-2$ fetus and falling to around $2 \%$ for a 2-1 fetus ( $2 \%$ recombination rate with CKMM). Since the phase is known from the previous generation, the lack of DNA from the dead child is not critical; prediction would have been possible in this pregnancy also.
Example 7 (fig 2c). Prenatal diagnosis; normal outcome. (Referred by Dr B C Clare Davison, Addenbrooke's Hospital, Cambridge.)

The proband and his wife were first seen for genetic counselling with a view to testing for informativeness in a future pregnancy. The second pregnancy occurred unexpectedly while DNA typing was still in progress. It can be seen that the father of the proband has passed the myotonic dystrophy gene to his son with the 1 marker allele (ApoCII/ TaqI). However, the proband has passed the normal allele 2 to the fetus, reducing its risk from $50 \%$ to $4 \%$. The pregnancy continued and resulted in a healthy son who remains well aged 2 years. Even if the child were to have inherited the myotonic dystrophy gene, evidence of disease would not be expected in early childhood with paternal transmission.

Example 8 (fig 2d). Prenatal diagnosis; abnormal outcome. (Referred by Dr C Verellen, Université Catholique de Louvain, Brussels.)

The proband requested prenatal diagnosis in her first pregnancy. She was herself affected, as were her three sibs and her nephew. Her affected father was dead. The family structure is not optimal for prediction, but typing of the whole kindred showed the most likely situation to be that the myotonic dystrophy gene was transmitted with the allele 1 of the marker locus (ApoCII/BanI). The chorionic villus sample typed $1-1$ giving a $92 \%$ probability of the fetus being affected. The karyotype was normal, 46,XX. After considerable discussion, the couple elected to continue the pregnancy; a congenitally affected female infant was born.

Example 9 (fig 2e). A partially informative family. (Referred by Dr D Siggers, Royal United Hospital, Bath.)

This family was ascertained when congenital myotonic dystrophy was diagnosed in the son who subsequently died at 9 weeks. Myotonic dystrophy was confirmed in the mother who had obvious myotonia, but had not previously regarded it as abnormal. It was uncertain which of her parents had transmitted the gene; her father had had cataracts removed but had no neuromuscular symptoms or signs. EMG showed numerous myotonic discharges. Testing with a view to future prenatal diagnosis was requested. Although genotyping clearly establishes the gene to be in phase with allele 1 of ApoCII/BanI, the mother and father of the proband are both heterozygous and the prior $50 \%$ risk cannot be altered for a fetus typing 2-1. Extraction of DNA from the congenitally affected son before death would not have changed the situation. 


\section{Discussion}

Our results show that it is possible in many cases to clarify the status of subjects at risk of myotonic dystrophy. The results of DNA studies should always be combined with clinical examination, slit lamp examination of the lens, and electromyography in the subject at risk in order to reduce errors in assignment of status. Table 2 clearly shows that an unhelpful pedigree structure and failure to identify which is the affected parent or grandparent are common reasons for an indeterminate result. Thus it is often necessary to investigate parents or grandparents in the same manner as for the consultand in cases of doubt (example 9). Lack of informativeness of probes also remains a problem and this is exacerbated by linkage disequilibrium between the ApoCII polymorphisms. ${ }^{15}$ This is likely to improve in future as new probes become available. As would be expected, more females than males requested genotype information (tables 2 and 3), because births of congenitally affected infants are invariably confined to females. ${ }^{4}$ Prenatal diagnosis has been acceptable to many affected women, especially those who already have a congenitally affected child. Unfortunately, there is no simple, early diagnostic test for myotonic dystrophy (such as creatine kinase analysis in Duchenne muscular dystrophy) and so it is too soon to validate prenatal diagnosis by scoring outcome; nevertheless, the observed outcomes of completed pregnancies have not yet shown any error. Although most couples will be informative for prenatal diagnosis, this cannot be guaranteed and it is far preferable to perform DNA analysis before pregnancy is undertaken. Most of the difficulties encountered occurred in pregnancies where informativeness had not been tested beforehand (table 4).

A further problem is the ethics of testing children. Our policy has been that children at risk should only be genotyped when there is a good clinical reason and not simply to relieve parental anxiety (examples 1 and 3 ). Neither do we type subjects at risk whose genotype would not significantly contribute to the consultand's result, except when they also wish to know their risk (example 7). By contrast, there is no ethical problem with testing congenitally affected children. Indeed, DNA should be extracted from all such persons and banked for future use as the prognosis is often poor. ${ }^{5}$

Presymptomatic testing and prenatal diagnosis for myotonic dystrophy by means of linked RFLPs is now soundly based. All affected subjects should have DNA banked for future use when other family members may require genotype information.
We would like to thank the many clinicians around the world who referred families and those scientists who kindly donated the probes used (Drs F E Baralle, S Humphries, T W McKeithan, and B Wieringa). This work was supported by the Department of Health, the Welsh Office, the Muscular Dystrophy Group of Great Britain, and the Muscular Dystrophy Association of America.

\section{References}

1 Harper PS. Myotonic dystrophy. London: Baillière Tindal, 1989.

2 Harper PS. Myotonic disorders. In: Engel AG, Banker BQ, eds. Myology. New York: McGraw-Hill, 1986.

${ }^{3}$ Meredith AL, Huson SM, Lunt PW, et al. Application of a closely linked polymorphism of restriction fragment length to counselling and prenatal testing in families with myotonic dystrophy. Br Med J 1986;293:1353-6.

${ }^{4}$ Harper PS. Congenital myotonic dystrophy in Britain. II. Genetic basis. Arch Dis Child 1975;50:514-21.

5 Harper PS. Congenital myotonic dystrophy in Britain. I. Clinical aspects. Arch Dis Child 1975;50:505-13.

${ }^{6}$ Lunt PW, Meredith AL, Harper PS. First-trimester prediction in fetus at risk for myotonic dystrophy. Lancet 1986;ii:350-1.

${ }^{7}$ Harper PS, Rivas ML, Bias WB, Hutchinson JR, Dyken PR, McKusick VA. Genetic linkage confirmed between the locus for myotonic dystrophy and the ABH-secretion and Lutheran blood group loci. Am J Hum Genet 1972;24:310-6.

${ }^{\circ}$ Eiberg H, Mohr J, Nielsen LS, Simonsen N. Genetics an linkage relationships of the $\mathrm{C} 3$ polymorphism. Discovery of $\mathrm{C} 3$ Se linkage and assignment of LES-C3-DM-Sc-PEPD-L t synteny to chromosome 19 . Clin Genet 1983;24:159-70.

"Shaw DJ, Meredith AL, Sarfarazi M, et al. The apolipoprotein CII gene: subchromososmal localisation and linkage to the myotonic dystrophy locus. Hum Genet 1985;70:271-3.

${ }^{10}$ Brunner HG, Korneluk RG, Coerwinkel-Driessen M, et al. Myotonic dystrophy is closely linked to the gene for muscle-type creatine kinase. (CKMM). Hum Genet 1989;81:308-10.

$"$ Korneluk RG, MacLeod HL, McKeithan TW, Brooks JD, MacKenzie AE. A chromosome 19 clone from a translocation breakpoint shows close linkage and linkage disequilibrium with myotonic dystrophy. Genomics 1989;4:146-51.

12 Maniatis T, Fritsch EF, Sambrook J. Molecular cloning: a laboratory manual. New York: Cold Spring Harbor Laboratory Publications, 1982.

${ }^{13}$ Harley HG, Brook JD, Rundle SA, et al. Localisation of the myotonic dystrophy locus to $19 \mathrm{q} 13.2-19 \mathrm{q} 13.3$ and its relationship to twelve polymorphic loci on $19 \mathrm{q}$ (in preparation).

${ }^{14}$ Griggs RC, Wood DS. Criteria for establishing the validity of genetic recombination in myotonic dystrophy. Neurology (Minneap) 1989;39:420-1.

is Wallis SC, Donald JA, Forrest LA, Williamson R, Humphries $\mathrm{SE}$. The isolation of a genomic clone containing the apolipoprotein $\mathrm{CII}$ gene and the detection of linkage disequilibrium between two common DNA polymorphisms around the gene. Hum Genet 1984;68:286-9.

Correspondence to $\mathrm{Dr}$ A M Norman, Institute of Medical Genetics, University of Wales College of Medicine, Heath Park, Cardiff CF4 4XN. 